\title{
Impact of stem cells in craniofacial regenerative medicine
}

\author{
Pedro A. Sanchez-Lara ${ }^{1,2,3,4,5}$ *, Hu Zhao ${ }^{4}$, Ruchi Bajpai ${ }^{4}$, Alaa I. Abdelhamid ${ }^{6}$ and David Warburton ${ }^{1,2,3,4,5}$ * \\ ${ }^{1}$ Children's Hospital Los Angeles, Keck School of Medicine, University of Southern California, Los Angeles, CA, USA \\ ${ }^{2}$ Department of Pediatrics, Keck School of Medicine, University of Southern California, Los Angeles, CA, USA \\ ${ }^{3}$ Department of Pathology, Keck School of Medicine, University of Southern California, Los Angeles, CA, USA \\ ${ }^{4}$ Center for Craniofacial Molecular Biology, Ostrow School of Dentistry, University of Southern California, Los Angeles, CA, USA \\ ${ }^{5}$ Developmental Biology and Regenerative Medicine Program, Saban Research Institute, Children's Hospital Los Angeles, Los Angeles, CA, USA \\ ${ }^{6}$ Tissue Engineering and Biomaterials Research Unit (TEBRU), Qassim College of Dentistry, Qassim University, Kingdom of Saudi Arabia
}

\section{Edited by:}

Anis Feki, Geneva University

Hospitals, Switzerland

Reviewed by:

Christian Morsczeck, University of Regensburg, Germany

Ivo Lambrichts, Hasselt University, Belgium

Catherine Chaussain, Université Paris

Descartes Paris Cité, France

\section{${ }^{*}$ Correspondence:}

Pedro A. Sanchez-Lara and David

Warburton, Developmental Biology

and Regenerative Medicine Program

Saban Research Institute, Children's

Hospital Los Angeles, 4650 West

Sunset BIvd, MS\#100, Los Angeles,

CA 90027, USA.

e-mail:Pedro.Sanchez@usc.edu;

dwarburton@chla.usc.edu

\begin{abstract}
Interest regarding stem cell based therapies for the treatment of congenital or acquired craniofacial deformities is rapidly growing. Craniofacial problems such as periodontal disease, cleft lip and palate, ear microtia, craniofacial microsomia, and head and neck cancers are not only common but also some of the most burdensome surgical problems worldwide. Treatments often require a multi-staged multidisciplinary team approach. Current surgical therapies attempt to reduce the morbidity and social/emotional impact, yet outcomes can still be unpredictable and unsatisfactory. The concept of harvesting stem cells followed by expansion, differentiation, seeding onto a scaffold and re-transplanting them is likely to become a clinical reality. In this review, we will summarize the translational applications of stem cell therapy in tissue regeneration for craniofacial defects.
\end{abstract}

Keywords: stem cell, craniofacial, regeneration

\section{INTRODUCTION}

Although conventional surgical treatments for congenital and acquired craniofacial problems continue to make progress, the final functional and cosmetic outcomes can be varied, unpredictable and sometimes unsatisfactory mostly because of complications, infections, and scar tissue. The promise of regenerative medicine brings new energy and hope for improved outcomes by replacing damaged or absent tissues with healthy regenerated tissue (Figure 1).

One potential stem cell based strategy for repairing craniofacial defects is the use of embryonic stem (ES) cells. ES cells are derived from the inner cell mass (ICM) of the blastocyst and possess the capacity to differentiate into all cell types (Evans and Kaufman, 1981; Martin, 1981; Thomson et al., 1998). However, the application of ES cells for clinical purposes has been limited by ethical issues, dysregulated ES cell differentiation, and immune rejection. In addition, the possibility of genomic instability and tumorigenesis still needs to be examined before any large-scale clinical experiments are planned.

The ability to generate induced pluripotency stem (iPS) cells is one of the major breakthroughs in stem cell study in recent years (Takahashi and Yamanaka, 2006; Takahashi et al., 2007). Somatic cells from human fibroblast cells can be reprogrammed into a primordial, ES-like state and are able to differentiate into all three germ layers (ectoderm, endoderm, and mesoderm). This technology offers a revolutionary approach for the introduction of autologous multipotential stem cells into patient-specific, tissue-specific regeneration and repair.
Applications of iPS cell technology to the clinic are still at a preliminary stage and face some of the same concerns as their ESC counterpart. Foremost amongst them is the issue of dysregulated growth (Li et al., 2008) and lack of methods for is ensuring accurate and complete reprogramming of differentiated somatic cells from progeny. The second issue of major concern is the potential for tumor growth and development from even micro contamination of undifferentiated cells. This is further compounded by the persistence of ectopic gene expression, since iPS cells are often produced by transduction of somatic cells with lentivirus encoding ectopic transgenes. There are concerns that the continuous expression of transgenes may bring the risk of abnormal tumor growth (Nelson et al., 2010). The next generation technologies using small molecules or alternative approaches to gene induction may address these limitations. Coupled with recent advances in identifying biomarkers to select against tumor forming pluripotent cells and robust techniques to differentiate the iPS and ES cells into lineage restricted stem cells, the potential therapeutic use of stem cells ideally suited for craniofacial repair is gaining ground (Alvarez-Manilla et al., 2010; Bajpai et al., 2010; Curchoe et al., 2010).

Tissue-specific postnatal stem cells have been isolated from a variety of organs and tissues, including but not limited to, bone marrow (Castro-Malaspina et al., 1980; Civin et al., 1984), neural tissue (Flax et al., 1998; Johansson et al., 1999), muscle (Chen and Goldhamer, 2003; Huard et al., 2003), and skin (Janes et al., 2002; Lavker and Sun, 2003). Compared to ES or iPS cells that self-renew indefinitely, tissue-specific adult stem cells also have 
significant self-renewal capability, but severely limited differentiation ability. In the craniofacial region, multiple types of stem cells have been recognized, including bone marrow mesenchymal stem cells (BMMSC), muscle satellite cells (MSCs), dental pulp stem cells (DPSCs), periodontal ligament stem cells (PDLSCs), and stem cells from human exfoliated deciduous (SHED teeth; Gronthos et al., 2000, 2002; Miura et al., 2003; Seo et al., 2004; Akintoye et al., 2006) (Figure 2).

In the current review, we aim to summarize the application of stem cell therapies in tissue regeneration of various craniofacial defects.

\section{SCAFFOLDS AND BIOMATERIALS}

Craniofacial reconstructive surgery manipulates available tissues in a three dimensional field, either by transferring tissue from a donor site or supporting and shaping the repair with artificial scaffolds and biomaterials. Biomaterials in stem cell tissue engineering and regeneration not only provide a supportive scaffold but also create an artificial niche that allows natural processes of stem cell renewal, proliferation, and differentiation while promoting vascularization, integration, adhesion, and survival of the newly generated tissue (Rossi et al., 2010a). Incorporating small molecules and growth or differentiation promoting factors within the biomaterials can further potentiate these natural repair processes resulting in efficient biological repair. The basic requirement for all biomaterial used for tissue engineering purposes is that it be inert and does not provoke a significant inflammatory response. However the tensile strength, biostability or biodegradability are features that will be favored in a context dependent manner. Inert stable scaffolds provide rigidity but lack the ability to remodel with age. While biodegradable scaffolds that provide transient threedimensional contour for the regenerating tissue are especially appealing for soft tissue repair but raise the concern of inadequate regeneration, inadequate mechanical properties of the newly formed tissue and sustained function over long periods of time.

\section{CRANIOFACIAL BONE TISSUE ENGINEERING AND STEM CELLS}

Current clinical approaches for reconstructing craniofacial bone defects include autologous bone grafts, allogeneic bone grafts, and prosthetic grafts such as titanium frameworks (Marchac, 1982;
Shenaq, 1988; Goodrich et al., 1992; Cowan et al., 2004). Stem cell based strategies are currently a promising approach in craniofacial bone tissue engineering (Figure 1).

Different cell sources have been used for repairing craniofacial bony defects. BMMSCs have been reported to be capable of multipotential differentiation. When cultured in the presence of dexamethasone, inorganic phosphate, and vitamin C, BMMSCs can be induced to become osteoblast-like cells in vitro and form calcified nodules (Gronthos et al., 1994). However, when transplanted into immunocompromised mice, only a subset of the BMMSCs was able to form ectopic bone in the host, suggesting that heterogeneity exists among BMMSCs (Kuznetsov et al., 1997; Gronthos et al., 2003). Successful repair of bony defects has been demonstrated in both calvarial and long bone in various animal models (Bruder et al., 1998; Krebsbach et al., 1998; Kon et al., 2000; Mankani et al., 2001). Autologous BMMSCs have also been used in clinical experiments to repair bony defects in the mandible. In a study conducted by Warnke and coworkers, autologous BMMSCs were seeded onto custom-made mandible scaffolds composed of titanium and bone mineral blocks containing BMP7. The construct was placed under the patient's skin for 7 weeks and then transplanted into the patient's mouth to repair the mandible defect. The patient showed significantly improved masticatory function and was satisfied with the esthetic outcome (Warnke et al., 2004).

Adipose-derived mesenchymal stem cells (AMCs) are also used for repairing craniofacial bone defects. AMCs are readily obtained via lipo-aspiration and expand easily in vitro. They are multipotential and capable of forming different types of tissue including muscle, bone, neural, and chondrocyte tissues (Zuk et al., 2001; Gimble and Guilak, 2003; Hicok et al., 2004). AMCs taken from human sources were shown to be able to form bone when seeded in an HA-TCP scaffold and transplanted into immunocompromised mice (Hicok et al., 2004). In a clinical experiment conducted by Cowan and coworkers, AMCs were expanded in vitro and seeded in apatite-coated, PLGA scaffolds. The construct was then transplanted into a human patient to repair a critical size calvarial bone defect. New bone formation was observed 2 weeks after transplantation and complete bony bridging was observed by 12 weeks. Over $90 \%$ of the new bone formation was contributed by the transplant (Cowan et al., 2004).

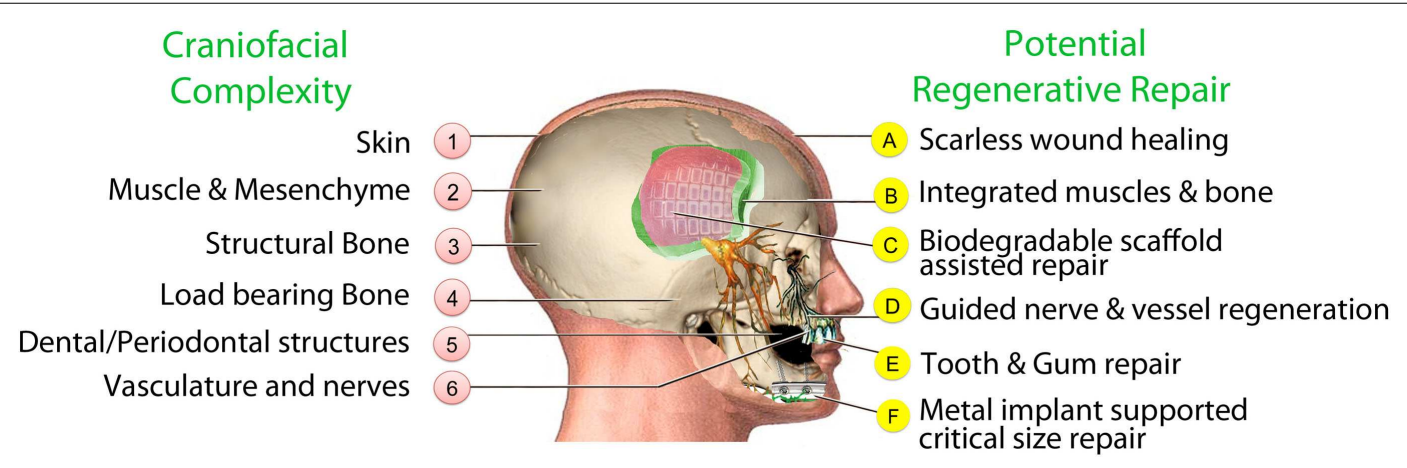

FIGURE 1 | Craniofacial structures and potential for regenerative repair. 


\section{A Pluripotent Stem Cells}

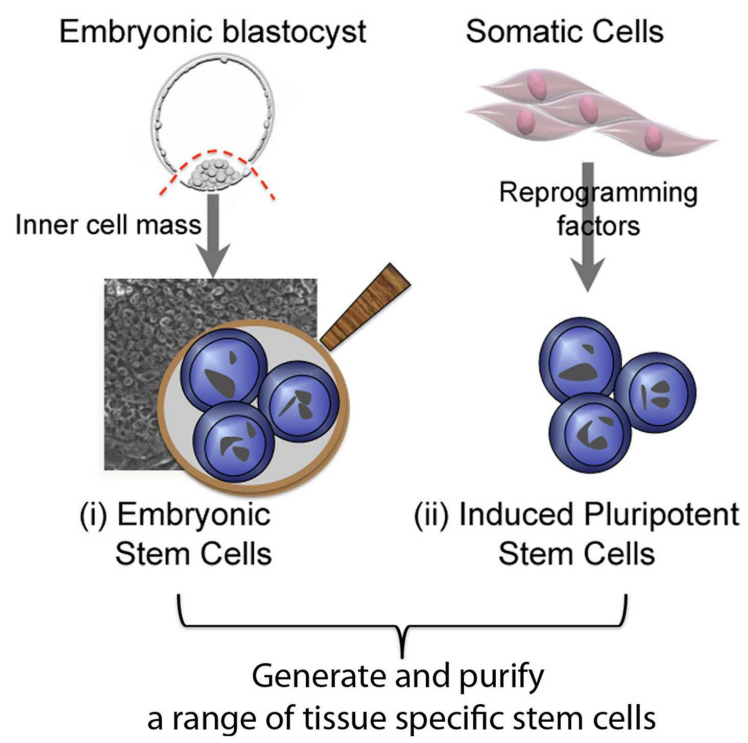

B Adult Stem Cells

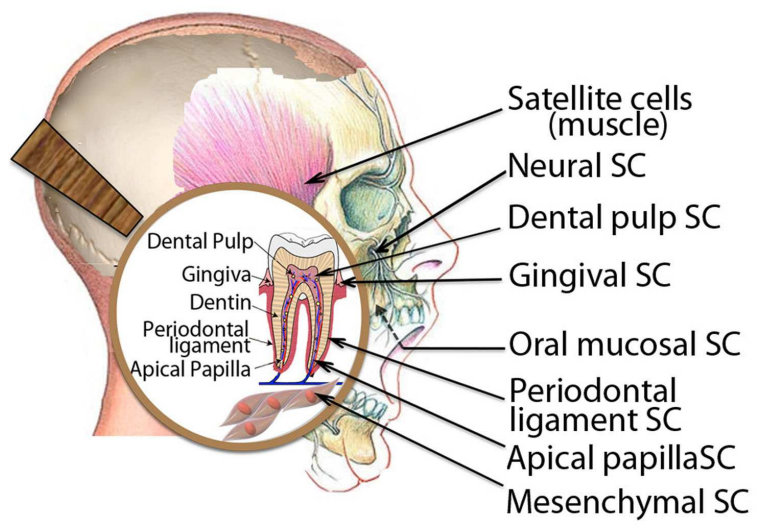

FIGURE 2 | Major sources of cells for craniofacial repair and regeneration. (A) Pluripotent stem cells, (B) Adult stem cells.

For tissue engineering purposes, stem cells are usually delivered with scaffolds. One critical requirement for the bone-engineering scaffold is osteoconductivity, which means the ability of the scaffold construct to integrate with the host bone (Zaky and Cancedda, 2009). It has been widely accepted that the HA-TCP combination provides the best bone integration ability and maintains a proper resorption rate (Cancedda et al., 2007). In addition, polymeric materials have also been widely tested as the scaffold. These scaffold materials are based on alpha-hydroxy acids and are usually composed of polyglycolic acid, poly-L-lactic acid, or both. They have limited osteoconductive ability but can be excellent scaffold materials when combined with HA for bone repair (Cancedda et al., 2007).

Besides supporting the cells, another important function of the scaffold is to deliver growth factors. Various growth factors promote angiogenesis and osteogenesis. For example, BMP2, TGFbeta, and VEGF all enhance bone formation from osteogenic cells (Rose et al., 2004; Yang et al., 2004; Montjovent et al., 2007; Oest et al., 2007). Transgenic BMMSCs that over express BMP-4 also enhance bone formation (Savarino et al., 2007). Despite the many informative and promising results, the effects of growth factors still need to be studied more thoroughly, considering some unexpected effects such as oncogenicity (Hunter and Avalos, 2000).

\section{SKELETAL MUSCLE TISSUE REGENERATION AND STEM CELLS}

Functional muscle regeneration is likely the most challenging task in craniofacial tissue regeneration, yet with the potential for the greatest impact. Muscle reconstruction plays a critical role in rebuilding functional craniofacial structures like cleft palate repair, whole face reconstruction from congenital or acquired deformities and tongue reconstruction after tumor resection. Current therapies require surgical tissue transfer from local or distant donor sites, which can generate secondary morbidity of volume loss and pain, with potential additional risks of infection and functional loss.

Multiple stem cell sources of skeletal muscle cells have been identified either within or outside the muscle compartments. Skeletal muscle precursors (myoblasts) can be derived from satellite cells (reserve cells located on the surface of mature myofibers underneath the basal lamina) or from cells lying beyond the myofiber, e.g., interstitial connective tissue or bone marrow. Both of these classes of cells may have stem cell properties (Grounds et al., 2002). In vivo, SCs can be characterized by their expression of Pax7 (Seale et al., 2000). SCs can be isolated through either mechanical or enzymatic disassociation from muscle fibers and can be expanded in vitro (Rosenblatt et al., 1995; Collins et al., 2005; Cerletti et al., 2008; Rossi et al., 2010b). After transplantation, they maintain a strong myogenic potential both in vitro and in vivo. SCs obtained from single fiber explants, then expanded and injected intramuscularly, showed poor proliferation and regeneration ability, yet freshly isolated SCs present better proliferative and regeneration potential (Beauchamp et al., 1999; Collins et al., 2005; Montarras et al., 2005; Rossi et al., 2010b). Therefore, the preferred method of delivering SCs might be to isolate SCs freshly from a muscle biopsy and deliver them directly, to avoid the disadvantages of in vitro culture.

Several other cell types have been identified as myogenic within the muscle compartment. The mesoangioblasts are associated with blood vessels and express early endothelial markers including Flk1, CD34, stem cell antigen-1, and VE-Cadherin (Barberi et al., 2007). They can proliferate for several passages with no obvious tumorigenic potential. Using co-culture with myoblasts, they can be easily induced into myoblasts (Cossu and Bianco, 2003). Some factors including integrin-alpha4, stromal cell derived factor-1 (SDF-1), and TNF-alpha promote the migration of wild type mesoangioblasts to dystrophic muscles by five fold, which enables the production of new muscle fibers expressing a normal amount of the mutated genes (Galvez et al., 2006). Another myogenic stem cell population within the muscle compartment is the pericyte. The pericyte can be characterized by expression of NG2 and PDGF receptor beta. Pericytes isolated from numerous 
human organs have been shown to be myogenic both in vitro and in vivo (Quattrocelli et al., 2011). Skeletal myogenic progenitors (SMPs) have been isolated based on betal-integrin and CXCR4 expression from skeletal muscle (Cerletti et al., 2008). SMPs were able to restore dystrophin expression and improve muscle function and histology when transplanted into dystrophic mice. SMP transplantation resulted in the rebuilding of a functional stem cell pool within the muscle compartment of the recipient mice.

Muscle stem cells (MuSCs) were also isolated by the specific expression of integrin-alpha7 and CD34. MuSCs injected into muscles of mice damaged with notexin were able to rebuild the host SC niche and generate new muscle fibers (Sacco et al., 2008).

Outside of the muscle compartment, BMMSCs are capable of undergoing myogenic differentiation (Bianco et al., 2008). After direct injection, BMMSCs can migrate to damaged muscle sites and undergo myogenic differentiation (Bianco et al., 2008). CD133+ cells into the blood stream have also been tested for their myogenic potential (Torrente et al., 2007). They can be induced in vivo and in vitro into myogenic progenitors and may be able to contribute to the treatment of muscular diseases together with other bone marrow derived progenitors.

Until now, there have been only a few human clinical trials of stem cell based strategies to treat muscular dystrophy, myocardial infarction and stress urinary incontinence by using SC or CD133+ cells (Tedesco et al., 2010). There have been no reports of regenerating the craniofacial skeletal muscles. Although they share many common properties with the limb skeletal muscles, craniofacial skeletal muscles also possess many unique features. Their embryonic origins are different from the limb muscles (McLoon et al., 2007). Craniofacial skeletal muscles express some immature myosin heavy chain isoforms not present in the limb muscles (McLoon et al., 2007). Moreover, craniofacial skeletal muscles, especially extraocular muscles (EOM) and laryngeal muscles (LM), contain a population of activated satellite cells that is nearly twofold more than that of the limb skeletal muscles (Renault et al., 2002). This raises the interesting possibility that craniofacial muscles might be a better source than limb muscles for obtaining progenitor cells to treat Duchenne and related muscular dystrophies or other musculoskeletal defects.

\section{DENTAL STEM CELLS AND TOOTH REGENERATION}

Human teeth are comprised of enamel, dentin, tooth, pulp, and cementum covering the root surface. The periodontal ligament surrounds and supports the tooth. Unlike bone, most hard tissue in the tooth does not undergo renewal after its formation; only dentin can regenerate itself internally upon injury, suggesting the existence of stem cell populations within the tooth pulp. One of the first dental related stem cell populations identified are the DPSCs (Gronthos et al., 2000). DPSCs are capable of differentiating into multiple types of tissue including odontoblast, bone, adipocyte, and neuron (Gronthos et al., 2000; Miura et al., 2003; Huang et al., 2009). In addition, SHED teeth pulp also possess multipotential differentiation ability (Miura et al., 2003). Both SHED and DPSCs are able to generate tissue resembling human tooth pulp under appropriate conditions (Cordeiro et al., 2008; Casagrande et al., 2010; Demarco et al., 2010; Sakai et al., 2010). Several studies have attempted to rebuild teeth in vitro by combining tooth pulp derived stem cells with proper scaffold materials (Young et al., 2002; Ohazama et al., 2004; Cordeiro et al., 2008). In the Ohazama study, different types of non-dental derived mesenchymal cells including ES cells, neural stem cells and adult BMMSCs were mixed with embryonic oral epithelium cells. The mesenchyme-epithelium cell mixtures were then delivered into kidney capsules of adult mice in an effort to recapitulate the classical dental epithelium-mesenchyme interactions which initiate and direct tooth development. All the mixtures resulted in the development of tooth-like structures and surrounding bone. This experiment indicated that it is possible to regenerate a tooth by mimicking the natural developmental process (Ohazama et al., 2004). Other studies have used DPSCs or SHED for treatment of disease of non-dental tissue such as muscle dystrophies, critical size bony defect, spinal cord damage, corneal injury, and even systemic lupus erythematosus (Nosrat et al., 2001; Kerkis et al., 2008; Seo et al., 2008; Monteiro et al., 2009; Ishkitiev et al., 2010; Yamaza et al., 2010).

Scaffolds provide a 3-D framework for cells and serve as an extracellular matrix for a finite period of time. Scaffolds provide an environment that allows both cell migration and proliferation, and may be fabricated in pre-determined shapes and composition (Nakashima and Akamine, 2005). The first scaffold material used successfully for tooth tissue engineering was a copolymer of PGA/PLLA and PLGA (Young et al., 2002), which are the most commonly used scaffold materials for tissue engineering studies. These scaffolds are biodegradable and biocompatible. Changing the component ratio can control the degradation rate of the PLLA/PGA scaffold. PLLA has also been used in many tooth tissue engineering studies, and tissue with morphology and structure resembling that of human tooth pulp has been generated after seeding dental pulp stem cells onto the PLLA scaffolds (Cordeiro et al., 2008; Casagrande et al., 2010; Demarco et al., 2010; Sakai et al., 2010). Odontoblast specific marker DMP-1 is detectable within scaffolds generated with gelatin or salt porogens (Demarco et al., 2010). In the future, the ability to control the shape of the tissue engineered tooth generated with appropriate scaffold materials will be a crucial step towards bringing the technique to the clinic (Modino and Sharpe, 2005).

\section{PERIODONTIUM TISSUE REGENERATION AND STEM CELLS}

Periodontal diseases affect $15 \%$ of the human adult population, with periodontal soft tissue loss and subsequent supporting bone resorption leading to loss of teeth (Mase et al., 2006). Current treatment approaches include the use of guided tissue regeneration, bioactive grafting materials, and application of bioactive molecules to induce regeneration, but the overall effects of these approaches are relatively modest and limited in practical applications. Regenerating the periodontium is a challenge in the treatment of periodontal diseases due to its complex structure, consisting of cementum, periodontal ligament, gingiva, and supporting bone. Thus, regeneration of the periodontium will require either multiple cell populations or a multipotential stem cell population. 
The Periodontal ligament is unique among the ligament and tendon tissues of the body, because it is the only soft tissue connecting two distinct hard tissues (McCulloch et al., 2000). The periodontal ligament suspends the tooth like a cushion in order transduce the mechanical load from the teeth evenly onto the supporting bone. Early studies of different animal models demonstrated that the periodontal tissues possess some regeneration activity, suggesting the existence of stem cell population within the periodontium (Karring et al., 1980; Nielsen et al., 1980; Nyman et al., 1980, 1982; Parlar et al., 2005). After depletion of various periodontal tissues, not only the periodontal ligaments, but also cementum and alveolar bone, can be regenerated, suggesting the presence of multipotential stem cell populations (Nielsen et al., 1980; Nyman et al., 1982; Parlar et al., 2005). Studies conducted on the human periodontium indicate the presence of a putative PDLSCs population (Seo et al., 2004), positive for MSC markers including STRO-1 and CD146 and able to differentiate into osteoblasts, adipocytes, and cementoblasts (Seo et al., 2004). Human PDLSCs expanded in vitro can contribute to periodontal tissue regeneration when transplanted into immunocompromised mice (Seo et al., 2004). PDLSCs are multipotential and can differentiate in vitro into various mesodermal (adipocyte, osteoblast, and chondrocyte), ectodermal (neuron), and endodermal (hepatocyte) cell types (Seo et al., 2005).

Cells of non-dental origins have also been tested for periodontal tissue regeneration. In 2004, Kawaguchi et al. and coworkers transplanted ex vivo expanded bone marrow MSCs into recipient dogs with periodontal defects. After a month, the transplanted cells were able to repair the defective periodontal tissue, including cementoblasts, periodontal ligament, and bone. This study suggested that bone marrow MSCs could be used as a source for periodontal tissue regeneration (Kawaguchi et al., 2004). Their following study indicated that regeneration by MSCs could be enhanced by addition of brain-derived neurotrophic factor (BDNF). BDNF increased the expression level of multiple bone and periodontal tissue related markers including OPN, BMP2, collagen I, ALPase, and VEGF (Takeda et al., 2005).

Cell sheet engineering has emerged as a novel alternative approach for periodontal tissue engineering without the disruption of critical cell surface proteins such as ion channels and growth factor receptors or cell-to-cell junction proteins. In this approach, PDL cells are isolated from an extracted tooth and cultured on temperature-responsive culture dishes at $37^{\circ} \mathrm{C}$. Transplantable cell sheets can be harvested by reducing the temperature to $20^{\circ} \mathrm{C}$ and transplanted into a bony defect (Huang and Zhang, 2011). This method results in an obvious cementum layer and Sharpey's fibers (Flores et al., 2008). Cell sheet engineering therefore allows for tissue regeneration by either direct transplantation of cell sheets to host tissues or the creation of three dimensional structures via the layering of individual cell sheets. By avoiding the use of any additional materials such as carrier substrates or scaffolds, the complications associated with traditional tissue engineering approaches, such as host inflammatory responses to implanted polymer materials, can be avoided. Thus, cell sheet engineering presents several significant advantages and can overcome many of the problems that have previously restricted tissue engineering with biodegradable scaffolds (Yang et al., 2005).

\section{ORAL MUCOSA STEM CELLS AND TISSUE ENGINEERING}

The human oral mucosa is highly active in terms of cell turnover and regeneration, which suggests the existence of one or more types of stem cell populations. Recently a stem cell population was identified from the lamina propria of adult human oral mucosa. This population was identified by positive expression of ES cell markers Oct4, Sox2, Nanog, and p75. These cells were localized in vivo to cord-like structures. They are highly proliferative in vitro and are able to differentiate into tissue of mesodermal (osteoblast, chondrocyte, and adipocyte), endodermal (endothelium), and ectodermal lineages (neuronal cells). Surprisingly, when transplanted into nude mice and treated with dexamethasone, these cells were able to form tumors containing mixed types of tissue (Marynka-Kalmani et al., 2010). This study indicates caution needs to be taken when applying stem cells for tissue engineering. In addition, Tran et al. (2003) reported the transdifferentiation of BMMSCs into buccal epithelial cells in human patients. By tracing the Y-chromosome of the bone marrow MSC male donor in the female recipient patients, they were able to localize the distribution of donor bone marrow MSCs cells on the buccal epithelial cells of the recipients. $1.8 \%$ of the recipients' cheek epithelial cells originated from the donor MSC and were detectable 56-1964 days after the procedure (Tran et al., 2003).

Regenerative therapy aims to reduce wound healing time and minimize scar formation. Wound healing of the skin is comprised of three phases: coagulation/early inflammation phase, late inflammation phase, and proliferative phase (Nauta et al., 2011). Although oral mucosa healing goes through the same three phases, it proceeds with an accelerated rate and reduced scar formation (Whitby and Ferguson, 1991). Fibroproliferative scars such as keloid and hypertrophic scars are rarely seen in the oral cavity (Wong et al., 2009). The only exception is the hard palate of the mouse which heals at a much slower rate than any other area of the oral mucosa (Graves et al., 2001). This unique property of the oral mucosa is critical to consider for any tissue engineering study. The first reason for the difference between oral mucosa healing and skin healing processes is the distinctive inflammatory response to the injury. The ratio of TGF-beta1 to TGF-beta3 is much lower in the oral mucosa than in the skin (Schrementi et al., 2008). In addition, fewer inflammatory cells infiltrate the mucosa wound at the initial stage and fewer inflammatory cytokines and chemokines are activated in the wound. Also, angiogenesis is less active in the oral mucosa wound than the skin, so that oral wound healing is quite similar to fetal skin wound healing (Mak et al., 2009).

To date, no satisfactory FDA-approved therapy is available for the treatment of scar tissue. Some reagents have been shown to possess anti-scarring effects. Topical hyaluronic acid and saponin may reduce scar formation by stimulating hyaluronic acid production (Mast et al., 1991). Some TGF-beta3 formulations and neutralizing antibody to TGF-betal or 2 have been shown to be effective at reducing scar formation (Rhett et al., 2008). Decorin can limit the duration of TGF-beta effects on inflammation and fibrosis (Jarvelainen et al., 2006). Other factors including TNFalpha, PDGF, FGF, VEGF, ILGF, EGF, and others have also demonstrated various effects on preventing scar formation (Lawrence, 1998). 


\section{TMJ TISSUE ENGINEERING AND STEM CELLS}

The temporomandibular joint (TMJ) is comprised of both osseous and cartilaginous structures. It can deteriorate due to injuries, osteoarthritis, or rheumatoid arthritis. The cartilage tissue has a limited capacity of intrinsic repair, so even minor lesions of injury may lead to progressive damage. Severe TMJ lesions need surgical replacement of the mandibular condyle (Sarnat and Laskin, 1992). Currently, a few studies on TMJ tissue engineering have been conducted in animal models. In one study, bone marrow MSCs were isolated from the long bone marrow and expanded in vitro under either osteogenic or chondrogenic culture conditions (Alhadlaq and Mao, 2003, 2004). The expanded osteogenic and chondrogenic cells were mixed with PEGDA hydrogel and seeded onto an adult human cadaver mandible condyle in two stratified yet integrated layers. These bi-layer constructs were then placed under nude mice skin for culture. After 4 weeks of implantation, de novo formation of human condyle-like structures was detectable replicating the relevant shape and dimensions. Chondrocytes and osteocytes of donor origin were identified in separated layers, and the two cell types infiltrated into the territory of each other, resembling the native condition. However, both chondrogenic and osteogenic layers showed suboptimal maturation, possibly due to an insufficient amount of cells. The same group also constructed a mandibular condyle scaffold by using CAD/CAM techniques and combined it with autologous bone marrow MSC cells. The construct was then transplanted into minipig TMJs. Evaluation and analysis after 1 and 3 months indicated bone regeneration

\section{REFERENCES}

Akintoye, S. O., Lam, T., Shi, S., Brahim, J., Collins, M. T., and Robey, P. G. (2006). Skeletal site-specific characterization of orofacial and iliac crest human bone marrow stromal cells in same individuals. Bone 38, 758-768.

Alhadlaq, A., and Mao, J. J. (2003). Tissue-engineered neogenesis of human-shaped mandibular condyle from rat mesenchymal stem cells. $J$. Dent. Res. 82, 951-956.

Alhadlaq, A., and Mao, J. J. (2004). Mesenchymal stem cells: isolation and therapeutics. Stem Cells Dev. 13, 436-448.

Alvarez-Manilla, G., Warren, N. L., Atwood, J. III, Orlando, R., Dalton, S., and Pierce, M. (2010). Glycoproteomic analysis of embryonic stem cells: identification of potential glycobiomarkers using lectin affinity chromatography of glycopeptides. J. Proteome Res. 9, 2062-2075.

Bajpai, R., Chen, D. A., Rada-Iglesias, A., Zhang, J., Xiong, Y., Helms, J., Chang, C. P., Zhao, Y., Swigut, T., and Wysocka, J. (2010). CHD7 cooperates with PBAF to control multipotent neural crest formation. Nature 463, 958-962.
Barberi, T., Bradbury, M., Dincer, Z., Panagiotakos, G., Socci, N. D., and Studer, L. (2007). Derivation of engraftable skeletal myoblasts from human embryonic stem cells. Nat. Med. 13, 642-648.

Beauchamp, J. R., Morgan, J. E., Pagel, C. N., and Partridge, T. A. (1999). Dynamics of myoblast transplantation reveal a discrete minority of precursors with stem cell-like properties as the myogenic source. J. Cell Biol. 144, 1113-1122.

Bianco, P., Robey, P. G., and Simmons, P. J. (2008). Mesenchymal stem cells: revisiting history, concepts, and assays. Cell Stem Cell 2, 313-319.

Bruder, S. P., Kraus, K. H., Goldberg, V. M., and Kadiyala, S. (1998). The effect of implants loaded with autologous mesenchymal stem cells on the healing of canine segmental bone defects. J. Bone Joint Surg. Am. 80, 985-996.

Cancedda, R., Giannoni, P., and Mastrogiacomo, M. (2007). A tissue engineering approach to bone repair in large animal models and in clinical practice. Biomaterials 28, 4240-4250.

Casagrande, L., Demarco, F. F., Zhang, Z., Araujo, F. B., Shi, S., and Nor, J. E.

of condyle shape and thus improvement of masticatory function (Mao et al., 2006).

\section{SUMMARY}

The impact of tissue engineering and potential applications of stem cells to reconstruct different dental, oral, and craniofacial tissues and structures extend well beyond craniofacial and dental practices. It is to be hoped that future stem cell based therapeutics will replace allograft and autologous tissue grafts, while improving long-term function and eliminating donor site morbidity.

\section{ACKNOWLEDGMENTS}

This work was made possible by institutional support from the Children's Hospital Los Angeles, Saban Research Institute, Center for Craniofacial and Molecular Biology and the Keck School of Medicine and the Ostrow School of Dentistry at the University of Southern California. PAS is supported by the Harold Amos Faculty Development Program through the Robert Wood Johnson Foundation, NIDCR Supplement 3R37DE012711-13S1 and the CHLA-USC Child Health Research Career Development Program (NIH K12-HD05954). Alaa Abdelhamid is supported by grants from the Kingdom of Saudi Arabia and has applied for additional research and training support from KSA together with David Warburton. David Warburton directs the California Institute for Regenerative Medicine Training Grant and Shared Laboratory at Children's Hospital Los Angeles.

(2010). Dentin-derived BMP-2 and odontoblast differentiation. J. Dent. Res. 89, 603-608.

Castro-Malaspina, H., Gay, R. E. Resnick, G., Kapoor, N., Meyers, P., Chiarieri, D., McKenzie, S., Broxmeyer, H. E., and Moore, M. A. (1980). Characterization of human bone marrow fibroblast colony-forming cells (CFUF) and their progeny. Blood 56, 289-301.

Cerletti, M., Jurga, S., Witczak, C. A., Hirshman, M. F., Shadrach, J. L., Goodyear, L. J., and Wagers, A. J. (2008). Highly efficient, functional engraftment of skeletal muscle stem cells in dystrophic muscles. Cell 134, 37-47.

Chen, J. C., and Goldhamer, D. J. (2003) Skeletal muscle stem cells. Reprod. Biol. Endocrinol. 1, 101.

Civin, C. I., Strauss, L. C., Brovall, C., Fackler, M. J., Schwartz, J. F., and Shaper, J. H. (1984). Antigenic analysis of hematopoiesis. III. A hematopoietic progenitor cell surface antigen defined by a monoclonal antibody raised against KG-1a cells. J. Immunol. 133, 157-165.

Collins, C. A., Olsen, I., Zammit, P. S., Heslop, L., Petrie, A., Partridge, T. A., and Morgan, J. E. (2005). Stem cell function, self-renewal, and behavioral heterogeneity of cells from the adult muscle satellite cell niche. Cell 122, 289-301.

Cordeiro, M. M., Dong, Z., Kaneko, T., Zhang, Z., Miyazawa, M., Shi, S., Smith, A. J., and Nor, J. E. (2008). Dental pulp tissue engineering with stem cells from exfoliated deciduous teeth. J. Endod. 34, 962-969.

Cossu, G., and Bianco, P. (2003). Mesoangioblasts - vascular progenitors for extravascular mesodermal tissues. Curr. Opin. Genet. Dev. 13, 537-542.

Cowan, C. M., Shi, Y. Y., Aalami, O. O., Chou, Y. F., Mari, C., Thomas, R., Quarto, N., Contag, C. $\mathrm{H}$., Wu, B., and Longaker, M. T. (2004). Adipose-derived adult stromal cells heal critical-size mouse calvarial defects. Nat. Biotechnol. 22, 560-567.

Curchoe, C. L., Maurer, J., McKeown, S. J., Cattarossi, G., Cimadamore, F., Nilbratt, M., Snyder, E. Y., BronnerFraser, M., and Terskikh, A. V. (2010). Early acquisition of neural crest competence during hESCs neuralization. PLoS ONE 5, e13890. doi:10.1371/journal.pone.0013890 
Demarco, F. F., Casagrande, L., Zhang, Z., Dong, Z., Tarquinio, S. B., Zeitlin, B. D., Shi, S., Smith, A. J., and Nor, J. E. (2010). Effects of morphogen and scaffold porogen on the differentiation of dental pulp stem cells. J. Endod. 36, 1805-1811.

Evans, M. J., and Kaufman, M. H. (1981). Establishment in culture of pluripotential cells from mouse embryos. Nature 292, 154-156.

Flax, J. D., Aurora, S., Yang, C., Simonin, C., Wills, A. M., Billinghurst, L. L., Jendoubi, M., Sidman, R. L., Wolfe, J. H., Kim, S. U., and Snyder, E. Y. (1998). Engraftable human neural stem cells respond to developmental cues, replace neurons, and express foreign genes. Nat. Biotechnol. 16, 1033-1039.

Flores, M. G., Yashiro, R., Washio, K., Yamato, M., Okano, T., and Ishikawa, I. (2008). Periodontal ligament cell sheet promotes periodontal regeneration in athymic rats. J. Clin. Periodontol. 35, 1066-1072.

Galvez, B. G., Sampaolesi, M., Brunelli, S., Covarello, D., Gavina, M., Rossi, B., Constantin, G., Torrente, Y., and Cossu, G. (2006). Complete repair of dystrophic skeletal muscle by mesoangioblasts with enhanced migration ability. J. Cell Biol. 174, 231-243.

Gimble, J., and Guilak, F. (2003). Adipose-derived adult stem cells: isolation, characterization, and differentiation potential. Cytotherapy 5, 362-369.

Goodrich, J. T., Argamaso, R., and Hall, C. D. (1992). Split-thickness bone grafts in complex craniofacial reconstructions. Pediatr. Neurosurg. 18, 195-201.

Graves, D. T., Nooh, N., Gillen, T., Davey, M., Patel, S., Cottrell, D., and Amar, S. (2001). IL-1 plays a critical role in oral, but not dermal, wound healing. J. Immunol. 167, 5316-5320.

Gronthos, S., Brahim, J., Li, W., Fisher, L. W., Cherman, N., Boyde, A., Denbesten, P., Robey, P. G., and Shi, S. (2002). Stem cell properties of human dental pulp stem cells. J. Dent. Res. 81, 531-535.

Gronthos, S., Graves, S. E., Ohta, S., and Simmons, P. J. (1994). The STRO$1+$ fraction of adult human bone marrow contains the osteogenic precursors. Blood 84, 4164-4173.

Gronthos, S., Mankani, M., Brahim, J., Robey, P. G., and Shi, S. (2000). Postnatal human dental pulp stem cells (DPSCs) in vitro and in vivo. Proc. Natl. Acad. Sci. U.S.A. 97, 13625-13630.

Gronthos, S., Zannettino, A. C., Hay, S. J., Shi, S., Graves, S. E., Kortesidis,
A., and Simmons, P. J. (2003). Molecular and cellular characterisation of highly purified stromal stem cells derived from human bone marrow. J. Cell Sci. 116, 1827-1835.

Grounds, M. D., White, J. D., Rosenthal, N., and Bogoyevitch, M. A. (2002). The role of stem cells in skeletal and cardiac muscle repair. J. Histochem. Cytochem. 50, 589-610.

Hicok, K. C., Du Laney, T. V., Zhou, Y. S., Halvorsen, Y. D., Hitt, D. C., Cooper, L. F., and Gimble, J. M. (2004). Human adipose-derived adult stem cells produce osteoid in vivo. Tissue Eng. 10, 371-380.

Huang, G. T., Gronthos, S., and Shi, S. (2009). Mesenchymal stem cells derived from dental tissues vs. those from other sources: their biology and role in regenerative medicine. $J$. Dent. Res. 88, 792-806.

Huang, S.-Y., and Zhang, D.-S. (2011). Periodontal Ligament Cell Sheet Engineering: A New Possible Strategy to Promote Periodontal Regeneration of Dental Implants. Rhode Island: Dental Hypotheses Westerly.

Huard, J., Cao, B., and Qu-Petersen, Z. (2003). Muscle-derived stem cells: potential for muscle regeneration. Birth Defects Res. C Embryo Today 69, 230-237.

Hunter, M. G., and Avalos, B. R. (2000). Granulocyte colony-stimulating factor receptor mutations in severe congenital neutropenia transforming to acute myelogenous leukemia confer resistance to apoptosis and enhance cell survival. Blood 95, 2132-2137.

Ishkitiev, N., Yaegaki, K., Calenic, B., Nakahara, T., Ishikawa, H., Mitiev, V., and Haapasalo, M. (2010). Deciduous and permanent dental pulp mesenchymal cells acquire hepatic morphologic and functional features in vitro. J. Endod. 36, 469-474.

Janes, S. M., Lowell, S., and Hutter, C. (2002). Epidermal stem cells. $J$. Pathol. 197, 479-491.

Jarvelainen, H., Puolakkainen, P., Pakkanen, S., Brown, E. L., Hook, M., Iozzo, R. V., Sage, E. H., and Wight, T. N. (2006). A role for decorin in cutaneous wound healing and angiogenesis. Wound Repair Regen. 14, 443-452.

Johansson, C. B., Svensson, M., Wallstedt, L., Janson, A. M., and Frisen, J. (1999). Neural stem cells in the adult human brain. Exp. Cell Res. 253, 733-736.

Karring, T., Nyman, S., and Lindhe, J. (1980). Healing following implantation of periodontitis affected roots into bone tissue. J. Clin. Periodontol. 7, 96-105.

Kawaguchi, H., Hirachi, A., Hasegawa, N., Iwata, T., Hamaguchi, H., Shiba, H., Takata, T., Kato, Y., and Kurihara H. (2004). Enhancement of periodontal tissue regeneration by transplantation of bone marrow mesenchymal stem cells. J. Periodontol. 75, 1281-1287.

Kerkis, I., Ambrosio, C. E., Kerkis, A., Martins, D. S., Zucconi, E., Fonseca, S. A., Cabral, R. M., Maranduba, C. M., Gaiad, T. P., Morini, A. C., Vieira, N. M., Brolio, M. P., Sant'anna, O. A., Miglino, M. A., and Zatz, M. (2008). Early transplantation of human immature dental pulp stem cells from baby teeth to golden retriever muscular dystrophy (GRMD) dogs: local or systemic? J. Transl. Med. 6, 35.

Kon, E., Muraglia, A., Corsi, A., Bianco, P., Marcacci, M., Martin, I., Boyde, A., Ruspantini, I., Chistolini, P., Rocca, M., Giardino, R., Cancedda, R., and Quarto, R. (2000). Autologous bone marrow stromal cells loaded onto porous hydroxyapatite ceramic accelerate bone repair in critical-size defects of sheep long bones. J. Biomed. Mater. Res. 49, 328-337.

Krebsbach, P. H., Mankani, M. H., Satomura, K., Kuznetsov, S. A., and Robey, P. G. (1998). Repair of craniotomy defects using bone marrow stromal cells. Transplantation 66, 1272-1278.

Kuznetsov, S. A., Krebsbach, P. H., Satomura, K., Kerr, J., Riminucci, M. Benayahu, D., and Robey, P. G. (1997). Single-colony derived strains of human marrow stromal fibroblasts form bone after transplantation in vivo. J. Bone Miner. Res. 12, 1335-1347.

Lavker, R. M., and Sun, T. T. (2003). Epithelial stem cells: the eye provides a vision. Eye (Lond.) 17, 937-942.

Lawrence, W. T. (1998). Physiology of the acute wound. Clin. Plast. Surg. 25, 321-340.

Li, J. Y., Christophersen, N. S., Hall, V. Soulet, D., and Brundin, P. (2008). Critical issues of clinical human embryonic stem cell therapy for brain repair. Trends Neurosci. 31, 146-153.

Mak, K., Manji, A., Gallant-Behm, C., Wiebe, C., Hart, D. A., Larjava, H. and Hakkinen, L. (2009). Scarless healing of oral mucosa is characterized by faster resolution of inflammation and control of myofibroblast action compared to skin wounds in the red Duroc pig model. J. Dermatol. Sci. 56, 168-180.
Mankani, M. H., Krebsbach, P. H., Satomura, K., Kuznetsov, S. A., Hoyt, R., and Robey, P. G. (2001). Pedicled bone flap formation using transplanted bone marrow stromal cells. Arch. Surg. 136, 263-270.

Mao, J. J., Giannobile, W. V., Helms, J. A., Hollister, S. J., Krebsbach, P. H., Longaker, M. T., and Shi, S. (2006). Craniofacial tissue engineering by stem cells. J. Dent. Res. 85, 966-979.

Marchac, D. (1982). Split-rib grafts in craniofacial surgery. Plast. Reconstr. Surg. 69, 566-567.

Martin, G. R. (1981). Isolation of a pluripotent cell line from early mouse embryos cultured in medium conditioned by teratocarcinoma stem cells. Proc. Natl. Acad. Sci. U.S.A. 78, 7634-7638.

Marynka-Kalmani, K., Treves, S., Yafee, M., Rachima, H., Gafni, Y., Cohen, M. A., and Pitaru, S. (2010). The lamina propria of adult human oral mucosa harbors a novel stem cell population. Stem Cells 28, 984-995.

Mase, J., Mizuno, H., Okada, K., Sakai, K., Mizuno, D., Usami, K., Kagami, H., and Ueda, M. (2006). Cryopreservation of cultured periosteum: effect of different cryoprotectants and pre-incubation protocols on cell viability and osteogenic potential. Cryobiology 52, 182-192.

Mast, B. A., Flood, L. C., Haynes, J. H., Depalma, R. L., Cohen, I. K., Diegelmann, R. F., and Krummel, T. M. (1991). Hyaluronic acid is a major component of the matrix of fetal rabbit skin and wounds: implications for healing by regeneration. Matrix 11, 63-68.

McCulloch, C. A., Lekic, P., and McKee, M. D. (2000). Role of physical forces in regulating the form and function of the periodontal ligament. Periodontol. 2000 24, 56-72.

McLoon, L. K., Thorstenson, K. M., Solomon, A., and Lewis, M. P. (2007). Myogenic precursor cells in craniofacial muscles. Oral Dis. 13, 134-140.

Miura, M., Gronthos, S., Zhao, M., Lu, B., Fisher, L. W., Robey, P. G., and Shi, S. (2003). SHED: stem cells from human exfoliated deciduous teeth. Proc. Natl. Acad. Sci. U.S.A. 100, 5807-5812.

Modino, S. A., and Sharpe, P. T. (2005). Tissue engineering of teeth using adult stem cells. Arch. Oral Biol. 50, 255-258.

Montarras, D., Morgan, J., Collins, C., Relaix, F., Zaffran, S., Cumano, A., Partridge, T., and Buckingham, M. (2005). Direct isolation of satellite cells for skeletal muscle regeneration. Science 309, 2064-2067. 
Monteiro, B. G., Serafim, R. C., Melo, G. B., Silva, M. C., Lizier, N. F., Maranduba, C. M., Smith, R. L., Kerkis, A., Cerruti, H., Gomes, J. A., and Kerkis, I. (2009). Human immature dental pulp stem cells share key characteristic features with limbal stem cells. Cell Prolif. 42, 587-594.

Montjovent, M. O., Mathieu, L., Schmoekel, H., Mark, S., Bourban, P. E., Zambelli, P. Y., LaurentApplegate, L. A., and Pioletti, D. P. (2007). Repair of critical size defects in the rat cranium using ceramicreinforced PLA scaffolds obtained by supercritical gas foaming. J. Biomed. Mater. Res. A 83, 41-51.

Nakashima, M., and Akamine, A. (2005). The application of tissue engineering to regeneration of pulp and dentin in endodontics. J. Endod. $31,711-718$

Nauta, A., Gurtner, G. C., and Longaker, M. T. (2011). Wound healing and regenerative strategies. Oral. Dis. 17, 541-549.

Nelson, T. J., Martinez-Fernandez, A., and Terzic, A. (2010). Induced pluripotent stem cells: developmental biology to regenerative medicine. Nat. Rev. Cardiol. 7, 700-710.

Nielsen, I. M., Ellegaard, B., and Karring, T. (1980). Kielbone in healing interradicular lesions in monkeys. $J$. Periodont. Res. 15, 328-337.

Nosrat, I. V., Widenfalk, J., Olson, L., and Nosrat, C. A. (2001). Dental pulp cells produce neurotrophic factors, interact with trigeminal neurons in vitro, and rescue motoneurons after spinal cord injury. Dev. Biol. 238, 120-132.

Nyman, S., Gottlow, J., Karring, T., and Lindhe, J. (1982). The regenerative potential of the periodontal ligament. An experimental study in the monkey. J. Clin. Periodontol. 9, 257-265.

Nyman, S., Karring, T., Lindhe, J., and Planten, S. (1980). Healing following implantation of periodontitis-affected roots into gingival connective tissue. J. Clin. Periodontol. 7, 394-401.

Oest, M. E., Dupont, K. M., Kong, H. J., Mooney, D. J., and Guldberg, R. E. (2007). Quantitative assessment of scaffold and growth factor-mediated repair of critically sized bone defects. J. Orthop. Res. 25, 941-950.

Ohazama, A., Modino, S. A., Miletich, I., and Sharpe, P. T. (2004). Stem-cellbased tissue engineering of murine teeth. J. Dent. Res. 83, 518-522.

Parlar, A., Bosshardt, D. D., Unsal, B., Cetiner, D., Haytac, C., and Lang, N. P. (2005). New formation of periodontal tissues around titanium implants in a novel dentin chamber model. Clin. Oral Implants Res. 16, 259-267.

Quattrocelli, M., Palazzolo, G., Floris, G., Schoffski, P., Anastasia, L., Orlacchio, A., Vandendriessche, T., Chuah, M. K., Cossu, G., Verfaillie, C., and Sampaolesi, M. (2011). Intrinsic cell memory reinforces myogenic commitment of pericyte-derived iPSCs. J. Pathol. 223, 593-603.

Renault, V., Thornell, L. E., Eriksson, P. O., Butler-Browne, G., and Mouly, V. (2002). Regenerative potential of human skeletal muscle during aging. Aging Cell 1, 132-139.

Rhett, J. M., Ghatnekar, G. S., Palatinus, J. A., O'Quinn, M., Yost, M. J., and Gourdie, R. G. (2008). Novel therapies for scar reduction and regenerative healing of skin wounds. Trends Biotechnol. 26, 173-180.

Rose, F. R., Hou, Q., and Oreffo, R. O. (2004). Delivery systems for bone growth factors - the new players in skeletal regeneration. J. Pharm. Pharmacol. 56, 415-427.

Rosenblatt, J. D., Lunt, A. I., Parry, D. J., and Partridge, T. A. (1995). Culturing satellite cells from living single muscle fiber explants. In vitro Cell. Dev. Biol. Anim. 31, 773-779.

Rossi, C. A., Pozzobon, M., and De Coppi, P. (2010a). Advances in musculoskeletal tissue engineering: moving towards therapy. Organogenesis 6, 167-172.

Rossi, C. A., Pozzobon, M., Ditadi, A., Archacka, K., Gastaldello, A., Sanna, M., Franzin, C., Malerba, A., Milan, G., Cananzi, M., Schiaffino, S., Campanella, M., Vettor, R., and De Coppi, P. (2010b). Clonal characterization of rat muscle satellite cells: proliferation, metabolism and differentiation define an intrinsic heterogeneity. PLoS ONE 5, e8523. doi:10.1371/journal.pone.0008523

Sacco, A., Doyonnas, R., Kraft, P., Vitorovic, S., and Blau, H. M. (2008). Self-renewal and expansion of single transplanted muscle stem cells. Nature 456, 502-506.

Sakai, V. T., Zhang, Z., Dong, Z., Neiva, K. G., Machado, M. A., Shi, S., Santos, C. F., and Nor, J. E. (2010). SHED differentiate into functional odontoblasts and endothelium. J. Dent. Res. $89,791-796$.

Sarnat, B. G., and Laskin, D. M. (1992). The Temporomandibular Joint: A Biological Basis for Clinical Practice. Philadelphia: Saunders.

Savarino, L., Baldini, N., Greco, M., Capitani, O., Pinna, S., Valentini, S., Lombardo, B., Esposito, M. T., Pastore, L., Ambrosio, L., Battista, S., Causa, F., Zeppetelli, S., Guarino, V., and Netti, P. A. (2007). The performance of poly-epsilon-caprolactone scaffolds in a rabbit femur model with and without autologous stromal cells and BMP4. Biomaterials 28 , 3101-3109.

Schrementi, M. E., Ferreira, A. M., Zender, C., and Dipietro, L. A. (2008). Site-specific production of TGFbeta in oral mucosal and cutaneous wounds. Wound Repair Regen. 16, 80-86.

Seale, P., Sabourin, L. A., GirgisGabardo, A., Mansouri, A., Gruss, P. and Rudnicki, M. A. (2000). Pax7 is required for the specification of myogenic satellite cells. Cell 102, 777-786.

Seo, B. M., Miura, M., Gronthos, S., Bartold, P. M., Batouli, S., Brahim, J., Young, M., Robey, P. G., Wang, C. Y., and Shi, S. (2004). Investigation of multipotent postnatal stem cells from human periodontal ligament. Lancet 364, 149-155.

Seo, B. M., Miura, M., Sonoyama, W., Coppe, C., Stanyon, R., and Shi, S. (2005). Recovery of stem cells from cryopreserved periodontal ligament. J. Dent. Res. 84, 907-912.

Seo, B. M., Sonoyama, W., Yamaza, T., Coppe, C., Kikuiri, T., Akiyama, K., Lee, J. S., and Shi, S. (2008). SHED repair critical-size calvarial defects in mice. Oral Dis. 14, 428-434.

Shenaq, S. M. (1988). Reconstruction of complex cranial and craniofacial defects utilizing iliac crestinternal oblique microsurgical free flap. Microsurgery 9, 154-158.

Takahashi, K., Tanabe, K., Ohnuki, M., Narita, M., Ichisaka, T., Tomoda, K. and Yamanaka, S. (2007). Induction of pluripotent stem cells from adult human fibroblasts by defined factors. Cell 131, 861-872.

Takahashi, K., and Yamanaka, S. (2006). Induction of pluripotent stem cells from mouse embryonic and adult fibroblast cultures by defined factors. Cell 126, 663-676.

Takeda, K., Shiba, H., Mizuno, N., Hasegawa, N., Mouri, Y., Hirachi, A., Yoshino, H., Kawaguchi, H., and Kurihara, H. (2005). Brain-derived neurotrophic factor enhances periodontal tissue regeneration. Tissue Eng. 11, 1618-1629.

Tedesco, F. S., Dellavalle, A., DiazManera, J., Messina, G., and Cossu, G. (2010). Repairing skeletal muscle: regenerative potential of skeletal muscle stem cells. J. Clin. Invest. 120, 11-19.

Thomson, J. A., Itskovitz-Eldor, J., Shapiro, S. S., Waknitz, M. A., Swiergiel, J. J., Marshall, V. S., and Jones, J. M. (1998). Embryonic stem cell lines derived from human blastocysts. Science 282, 1145-1147.

Torrente, Y., Belicchi, M., Marchesi, C., Dantona, G., Cogiamanian, F., Pisati, F., Gavina, M., Giordano, R., Tonlorenzi, R., Fagiolari, G., Lamperti, C., Porretti, L., Lopa, R., Sampaolesi, M., Vicentini, L., Grimoldi, N., Tiberio, F., Songa, V., Baratta, P., Prelle, A., Forzenigo, L., Guglieri, M., Pansarasa, O., Rinaldi, C., Mouly, V., Butler-Browne, G. S., Comi, G. P., Biondetti, P., Moggio, M., Gaini, S. M., Stocchetti, N., Priori, A., D'angelo, M. G., Turconi, A., Bottinelli, R., Cossu, G., Rebulla, P., and Bresolin, N. (2007). Autologous transplantation of muscle-derived CD133+ stem cells in Duchenne muscle patients. Cell Transplant. 16, 563-577.

Tran, S. D., Pillemer, S. R., Dutra, A. Barrett, A. J., Brownstein, M. J., Key, S., Pak, E., Leakan, R. A., Kingman, A., Yamada, K. M., Baum, B. J., and Mezey, E. (2003). Differentiation of human bone marrow-derived cells into buccal epithelial cells in vivo: a molecular analytical study. Lancet 361, 1084-1088.

Warnke, P. H., Springer, I. N., Wiltfang, J., Acil, Y., Eufinger, H., Wehmoller, M., Russo, P. A., Bolte, H., Sherry, E., Behrens, E., and Terheyden, H. (2004). Growth and transplantation of a custom vascularised bone graft in a man. Lancet 364, 766-770.

Whitby, D. J., and Ferguson, M. W. (1991). The extracellular matrix of lip wounds in fetal, neonatal and adult mice. Development 112, 651-668.

Wong, J. W., Gallant-Behm, C., Wiebe, C., Mak, K., Hart, D. A., Larjava H., and Hakkinen, L. (2009). Wound healing in oral mucosa results in reduced scar formation as compared with skin: evidence from the red Duroc pig model and humans. Wound Repair Regen. 17, 717-729.

Yamaza, T., Kentaro, A., Chen, C., Liu, Y., Shi, Y., Gronthos, S., Wang, S., and Shi, S. (2010). Immunomodulatory properties of stem cells from human exfoliated deciduous teeth. Stem Cell Res. Ther. 1, 5.

Yang, J., Yamato, M., Kohno, C., Nishimoto, A., Sekine, H., Fukai, F., and Okano, T. (2005). Cell sheet engineering: recreating tissues without biodegradable scaffolds. Biomaterials 26, 6415-6422.

Yang, X. B., Whitaker, M. J., Sebald, W., Clarke, N., Howdle, S. M., Shakesheff, K. M., and Oreffo, R. O. (2004). 
Human osteoprogenitor bone formation using encapsulated bone morphogenetic protein 2 in porous polymer scaffolds. Tissue Eng. 10, 1037-1045.

Young, C. S., Terada, S., Vacanti, J. P., Honda, M., Bartlett, J. D., and Yelick, P. C. (2002). Tissue engineering of complex tooth structures on biodegradable polymer scaffolds. $J$. Dent. Res. 81, 695-700.

Zaky, S. H., and Cancedda, R. (2009). Engineering craniofacial structures: facing the challenge. J. Dent. Res. 88 , 1077-1091.
Zuk, P. A., Zhu, M., Mizuno, H., Huang, J., Futrell, J. W., Katz, A. J., Benhaim, P., Lorenz, H. P., and Hedrick, M. H. (2001). Multilineage cells from human adipose tissue: implications for cell-based therapies. Tissue Eng. 7, 211-228.

Conflict of Interest Statement: David Warburton and CHLA hold intellectual property on amniotic fluid derived stem and progenitor cells and their therapeutic applications and are in the process of forming AmnioCure, a stem cell therapeutics company. The above authors do not have any other commercial or financial relationships that could be construed as a potential conflict of interest and/or have disclosed all relationships financial, commercial or otherwise that might be perceived by the academic community as representing a potential conflict of interest.

Received: 31 January 2012; paperpending published: 21 February 2012; accepted: 21 May 2012; published online: 21 June 2012.

Citation: Sanchez-Lara PA, Zhao H, Bajpai R, Abdelhamid AI and Warburton D
(2012) Impact of stem cells in craniofacial regenerative medicine. Front. Physio. 3:188. doi: 10.3389/fphys.2012.00188

This article was submitted to Frontiers in Craniofacial Biology, a specialty of Frontiers in Physiology.

Copyright (c) 2012 Sanchez-Lara, Zhao, Bajpai, Abdelhamid and Warburton. This is an open-access article distributed under the terms of the Creative Commons Attribution Non Commercial License, which permits non-commercial use, distribution, and reproduction in other forums, provided the original authors and source are credited. 